


\title{
Narrativas transitorias en la pintura histórica de José Effio ${ }^{1}$
}

\author{
Diego Paitán Leonardo \\ Universidad Nacional Mayor de San Marcos \\ diego.paitan@unmsm.edu.pe \\ Lima-Perú \\ Marianela Béjar Romero \\ Universidad Nacional Mayor de San Marcos \\ manebejar1@gmail.com \\ Lima-Perú \\ Cuando el misterio es demasiado \\ impresionante, es imposible desobedecer \\ Antoine de Saint-Exupéry
}

\section{Resumen}

El presente artículo cuestiona la valoración otorgada desde la opinión y la historiografía del arte, respecto a la biografía, al presunto origen étnico de mulato y la categoría de costumbrista del pintor José Effio Machuca (1853-1914). Además, se propone que, como lecturas particulares sobre su contemporaneidad, trató en la pintura de historia, diversas ideas sobre lo fúnebre, el héroe, la tradición y la modernidad.

Palabras clave: héroe, fúnebre, tradición, modernidad

\begin{abstract}
This article questions the assessment given from the opinion and the art historiography, regarding the biography, to the alleged ethnic origin of mulatto and the category of costumbrist of the painter José Effio Machuca (1853-1914). In addition, it is proposed that, as particular readings on his contemporaneity, he treated in the history painting, diverse ideas on the funereal, the hero, the tradition and the modernity.
\end{abstract}

Keywords: hero, funeral, tradition, modernity

José Effio Machuca (1853-1914) es aún hoy en día un enigma. Pintor nacido en Monsefú, Lambayeque, y radicado en Lima en el último tercio del siglo XIX, hasta hace unos años subsistía el concepto de Effio como pintor de cuadros de costumbres ${ }^{2}$ y como continuador del estilo y tema de Francisco "Pancho" Fierro (1807-1879). La reducción a las dos categorías señaladas responde a la sistemática imprecisión científica iniciada por la opinión ${ }^{3}$. Como recurso, un punto de partida fue analizar el valor de la atención sobre sus obras, puesto que los investigadores trazaron proyecciones y comentarios sesgados sin documentarse con rigurosidad. Respecto a las formas de atención y el conflicto de la opinión, el crítico literario Frank Kermode en Forms of Attention (1985) detectó que la manipulación informativa influye en las atenciones sobre obras de arte y artistas y, en ese sentido, filtró posibles contenidos trascendentales. De hecho, la transmisión de relatos orales, anécdotas y presunciones definió la clasificación valorativa inicial de exponentes y objetos artísticos

1 A la memoria de Rafael Hastings. Los autores agradecen a Federico Vigil (Parroquia San Pedro de Lambayeque), Laura Gutiérrez (Archivo Arzobispal de Lima), María Eugenia Abadía (Museo Fortaleza Real Felipe); asimismo, a José Torre Bohl, Luis Eduardo Wuffarden, Gabriela Lavarello, Nanda Leonardini, Ana Karina Saldaña, Jonathan Saona, Sofía Pachas y Horacio Rico por la asistencia documental y anotaciones sustanciales.

2 “[...] lo que importa en él [José Effio] es su obra costumbrista” (Núñez, 1975, p. 142). “José Effio] destaca por su obra costumbrista” (Mujica, 2013, p. 190). Los dos extremos temporales mantienen la misma calificación.

3 Información llana previa al análisis especializado y que provee teorías de legitimidad. 
a la posteridad (Kermode, 1985). Ese fue el dilema de Sandro Boticelli y William Shakespeare, quienes luego de un tiempo de oscuridad, fueron reivindicados en el siglo XIX. La pasión, antes que la certeza científica, fue, en muchos casos, el ingrediente concluyente, pero también se debió al cambio de sensibilidad, una búsqueda desde la modernidad por el origen y continuidad del gusto pretérito, aquel tomado como tradicional en cuanto a temas, disciplinas y artistas.

Este estudio se divide en dos puntos: en primer lugar, un balance de las incorrecciones historiográficas que afectaron su afiliación étnica, clasificación estilística y temática, confrontándose a ellos documentos oficiales sobre su vida personal. En segunda instancia, se plantea que el binomio tradición-modernidad, la figura del héroe y lo fúnebre, interactúan como aportes particulares y simbólicos del artista, congregados en las pinturas de historia y presentes en otros géneros.

\section{Consideraciones biográficas}

Hijo natural de Andrés Effio ${ }^{4}$ y Encarnación Machuca, José Effio fue bautizado a un día de nacido, el 16 de marzo de 1853 en la iglesia de San Pedro de Monsefú, según consta en la partida de bautismo:

José Efio. Año del Señor. Mil ochosientos sincuenta y tres en dies y seis de marzo yo S. presbítero Dn. Tomas Valera teniente de cura/ en esta doctrina de Sn. Pedro de Monsefu/ en su Santa Yglesia y pila bautismal ba/ utize, puse óleo y crisma a José un día/ de nasido hijo natural ${ }^{5}$ de Andres Efio/ y Encarnasión Machuca, fueron los pa/ drinos José Ramos Llontop [ilegible] y Dña./ Catalina Llontop a quienes advertí su obli/ gacion y parentesco espiritual y para q/ conste lo firmo/ Tomas Valera. ${ }^{6}$

Este documento cancela todas las presunciones sobre su fecha y lugar de nacimiento. ${ }^{7}$ En particular, la partida de defunción de su esposa, Jesús Pérez Lugones, fallecida en 1904, fue el principal error surgido desde los documentos oficiales que fue aceptado como canon biográfico. Allí se indica que Effio tenía 45 años, infiriéndose que nació en 1859.

Es aún desconocida la etapa lambayecana de Effio, así como las decisiones personales que lo llevaron a emigrar de Monsefú a Lima. ${ }^{8}$ El registro más temprano sucede a los dieciséis años. Effio, instalado en la capital, apareció como expositor de cuadros al carboncillo

4 En una conversación personal, Nanda Leonardini atribuyó la presunta nacionalidad italiana del padre por la raíz fonética del apellido.

5 El término "natural" alude a una condición diferente a la de "legítimo": era fruto de una unión extramatrimonial.

6 Archivo Parroquial de la iglesia de San Pedro de Monsefú. Libro de Bautismos, Libro VIII, Año 1853, Folio 205.

7 Para Luis Ugarte, amigo y primer biógrafo, Effio murió a los 58 años (1914, p. 7), dando a entender que nació en 1856. En 1984, Juan Manuel Ugarte Eléspuru precisó que Effio nació en 1840 y murió en 1907 (p. 16). En 2001 reconsideró su fecha de nacimiento a 1845, aunque ignoró el año de defunción (Ugarte, 2001, p. 295). Según Natalia Majluf(1997, p. 3), José Effio nació en 1840 y realizó su primera exposición en Lima en 1869. Para Nanda Leonardini, Effio nació en 1858, pero no precisó año de muerte (1998, p. 175). Asunto más grave fue que Teodoro Núñez Ureta expresara que el grabador Evaristo San Cristóbal conoció a Effio en 1917 (1975, p. 142) cuando el primero había muerto en 1900. En 1935, Jenaro Herrera lo renombró llamándolo "el pintor nacional Enrique Effio”, autor de La Fundación, obra erróneamente hecha en 1900 (p. 20). Para Guillermo Tello, Effio nació en Lima en 1840 y falleció en 1917 (1997, p. 116). En 1994, El Heladero de José Effio, expuesto en el Centro Cultural del Banco Wiesse, fue considerado como una impresión pictórica furtiva de un artista europeo durante su paso por la Lima decimonónica. Fue expuesta junto a obras de trashumantes como Auguste Bonnaffé, Teodoro Prisquet y Johann Moritz Rugendas (Tovar, 1994, p. 57), bajo la curaduría de José Torres Bohl.

8 Según los informes realizados por diversos vecinos, la villa de Monsefú apuntaba a constituirse como ciudad hacia 1870 por su crecimiento demográfico, aumento de la producción manufacturera de tejidos gracias a la agricultura, así como el comercio de diversos bienes (Macera, 2000, pp. 21-26). La relación entre el artista y el norte peruano no se reduce a este breve extracto de su localidad natal. En una colección particular existe un óleo que representa una perspectiva del Club Libertad de Trujillo con la inscripción apócrifa "Effio". No está fechada, pero su existencia implica que el artista, limitado al escenario limeño por la crítica posterior, tuvo trascendencia regional, al punto que fue copiado y víctima de falsificación. 


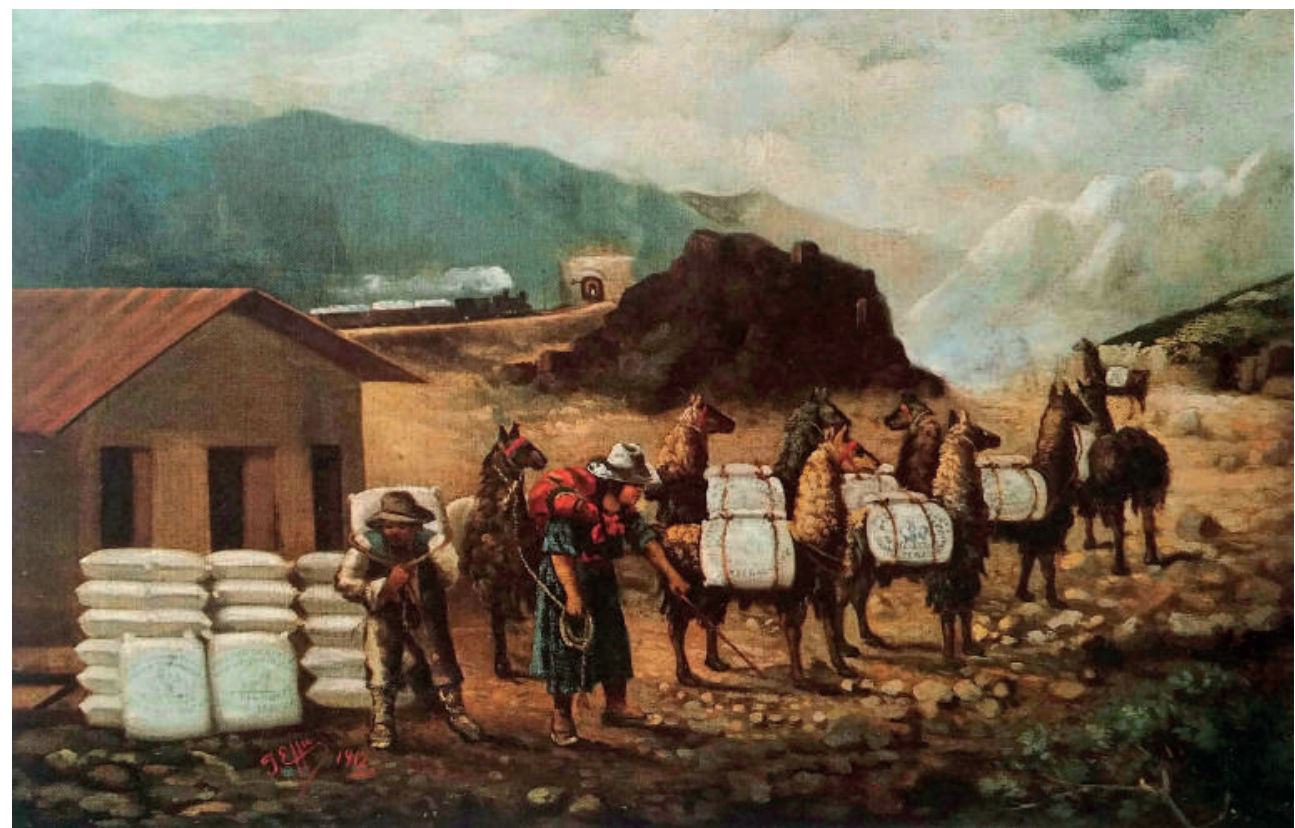

Fig.1. José Effio. Arrieros trasportando sal (1912). Óleo sobre lienzo. Reproducido en Catálogo XIX Subasta anual del MALI (2014). Edición Juan Gómez.

colgados en el primer patio, según se constata en el catálogo de la Exposición Industrial de Lima realizada el 28 de julio de $1869 .{ }^{9}$ Su presencia en el escenario limeño se torna activa hasta su participación en el certamen organizado por la filántropa Adelina Concha de Concha en 1891, con el óleo El primer anatomista. El primer premio resulta una beca de estudios, pero es descalificado por "poseer cierto prestigio" (Leonardini, 1998, p. 175).

En 1896 se casó con la dama limeña Josefa ${ }^{10}$ Pérez Lugones en la parroquia de San Lázaro del Rímac. ${ }^{11}$ En ese mismo año, el caudillo Nicolás de Piérola irrumpe y asume el poder político tras vencer a las facciones del presidente Andrés Avelino Cáceres, asunto que José Effio sintetizó en su interpretación de la histórica entrada por Cocharcas ${ }^{12}$ (Fig. 3). Durante su compromiso marital, Effio residió en la calle de Belaochaga ${ }^{\circ}{ }^{2} 29$, actualmente calle Nápoles, en el Cercado de Lima. ${ }^{13}$

9 El hecho resulta significativo porque coincidió con reconocidos artistas locales, como Manuel María del Mazo, Juan de Dios Ingunza, Federico del Campo e Ignacio Merino, este último, miembro de la primera generación de artistas republicanos. Es posible que, como señalaran algunos biógrafos, el aprendizaje técnico con sus maestros atribuidos Leonardo Barbieri, Ramón Muñiz y Francisco Masías, los dos últimos exponentes en el evento, favorecieran su participación en el certamen.

10 En la partida de defunción figura como Jesús Pérez.

11 Archivo de actas matrimoniales, Libro 15, folio 318, Parroquia de San Lázaro, Rímac. AAL. José Effio declaró tener 38 años, mientras su esposa, Josefa Pérez, 32. El padrino y el testigo de la unión, respectivamente, fueron los artistas Augusto Mago y Ricardo Suárez. Resalta la insolvencia de la pareja en el costo del proceso conyugal.

12 Recibió el nombre de La Coalición de Lima (1896).

13 Partida 315. Registro del Estado Civil y Estadística del Concejo distrital de San José de Surco. Se presenta como "casado, artista pintor, peruano, natural de Lambayeque, Perú". Jesús Pérez de Effio fue una dama limeña, hija legítima de Manuel Pérez y Melchora Lugones, de "raza mestiza”, domiciliada en Barranco, calle de Santo Toribio sin número, muerta a la edad de 51 años el 20 de abril de 1904. A través de Núñez Ureta se conoce que Effio tuvo un taller al frente de la pileta de la iglesia de La Merced (1975, p. 142), lo cual da a entender dos propósitos, el sustento económico y la labor docente. El taller lo conectaba con espacios culturales representativos de su tiempo, como el Hotel Maury, edificio en donde realizó pintura mural para el primer piso. 
Caso enigmático pero que cierra los diversos datos erróneos es la partida de defunción, ${ }^{14}$ la cual indica que Effio murió a los 50 años. Como se constató, falleció a los 61 años.

La tesis sobre su presunta condición étnica de pintor mulato y la irregular calidad técnica de su obra, debido en parte a la incapacidad de emigrar a los epicentros culturales hegemónicos, se basó sobre un prejuicioso parentesco con "Pancho" Fierro, referente plástico coetáneo, en quien se creyó corresponder características similares. Determinamos que no existe desde los documentos oficiales ni consignado por sus biógrafos, una ascendencia étnica, así como una crítica artística uniforme. No estamos de acuerdo, para el caso de Effio, con el prejuicio forzado de las limitaciones sociales y personales como alteraciones del rendimiento artístico sin comprobación, solo bajo el presupuesto de ser "mulato" e "hijo de italiano pobre" que, por su condición étnica y económica, no podría aprender arte o irse al extranjero (Leonardini, 1998, p. 175). Respecto a lo mulato, ${ }^{15}$ Fierro obtuvo esa categoría por tratarse del hijo de un sacerdote de ascendencia española con una esclava negra. ${ }^{16}$ Desde aquella polaridad de estratos sociales y étnicos, representó escenarios y personalidades de Lima que lo catapultaron como símbolo de la identidad local amparado en el costumbrismo. El vínculo entre Effio y Fierro se da, además de la trasmisión del mote de mulato ${ }^{17}$ en las condiciones de muerte que ambos tuvieron: apoplejía producto de una tuberculosis en el Hospital 2 de Mayo, ambos puestos en un nicho temporal en el Cementerio Presbítero Maestro y arrojados a la fosa común. A partir de estos condicionantes, los investigadores impusieron una trasmisión del legado del costumbrismo pictórico hacia fin del siglo.

El estrecho vínculo entre ambos artistas se detecta al distinguirse en Effio las características de la herencia panchofierrista que perciben sus críticos, sintetizado en la opinión de Núñez Ureta: factura "primitiva" de "tipos y costumbres de Lima", y aunque "pintor de cuadros históricos técnicamente malos", en sus obras estereotipadas -costumbristas- pueden hallarse "las raíces de un verdadero arte nacional" (1975, p. 142). En Effio, al no constatarse las presunciones, se utilizaron sus obras costumbristas como claves autobiográficas que relatarían un origen étnico aparente. A través de un examen general, Effio congregó diferentes tradiciones culturales (africanas, mestizas e indias), reveladas en el tema, acto o personajes representados, por lo que no privilegió alguno sobre otro. La representación de mulatos se da en óleos, como El primer tercio, Vivanderas y Retén del Puente Balta (1896), en tanto los indígenas contemporáneos fueron representados en Arrieros trasportando sal (1912), y los indígenas históricos en la Fundación de Lima (1897-99) y Cahuide en la defensa de Sacsayhuaman (1901). Bajo el argumento de la proyección simbólica de la ascendencia, los presuntos orígenes italianos no existen, por carecer de composiciones donde puedan ser identificados. Finalmente, el cuestionamiento de lo mulato radica en que la gravitación de lo costumbrista inhabilitó la amplia producción artística que poseía y con la que sobresalió en su contexto.

14 Sus restos estuvieron en el Cuartel San Felipe, letra C, nicho temporal 161, según el libro 02570, folio 232. Archivo de la Beneficencia de Lima.

15 Según Garcilaso, en el siglo XVII el sistema de castas virreinal dispuso al mulato como fruto de la unión entre negro(a) con india(o). La diferenciación racial fue promovida por la exploración científica en los reinos americanos en el siglo XVIII, entre cuyos bienes materiales demostrativos fueron los óleos "de castas" realizados en México y Perú. Para el caso peruano véase los cuadros del mestizaje del virrey Amat (c. 1770), en especial el lienzo n. ${ }^{\circ}$ 9: Mulata/ con/ Español. Produsen. Mulatos. Esto varió en el tránsito de los siglos XVIII y XIX, donde se convencionalizó como tal al hijo de blanco con negra, mientras que se llamó zambo al cruce de negro con blanca. Respecto a la clasificación racial en el siglo XIX, véase el estudio de José Clavero (1885) en Demografía de Lima en 1884. Lima: Imprenta de Juan Francisco Solís, p. 63.

16 El padre, Nicolás Mariano Rodríguez del Fierro, fue cura y vicario de las Doctrinas de San Damián de la Provincias de Huarochirí y de Huañec en Yauyos, ambas de Lima. (León, 2004, p. 116). La madre, María del Carmen Fierro, fue hija de otra esclava llamada Rita, de "casta banguela” (León, 2004, p. 91).

17 Mulato con "dotes de observador socarrón agudo que lo emparentan con el estilo temático de Fierro" (Ugarte, 1984, p. 16); mulato y autodidacta (Tello, 1997, p. 116), "hijo de italiano y mulata", opinión sin documento legal que corrobore esta ascendencia (Leonardini, 1998, p. 175); "se dice que era mulato", sin precisar fuente (Ugarte, 2001, p. 295). 


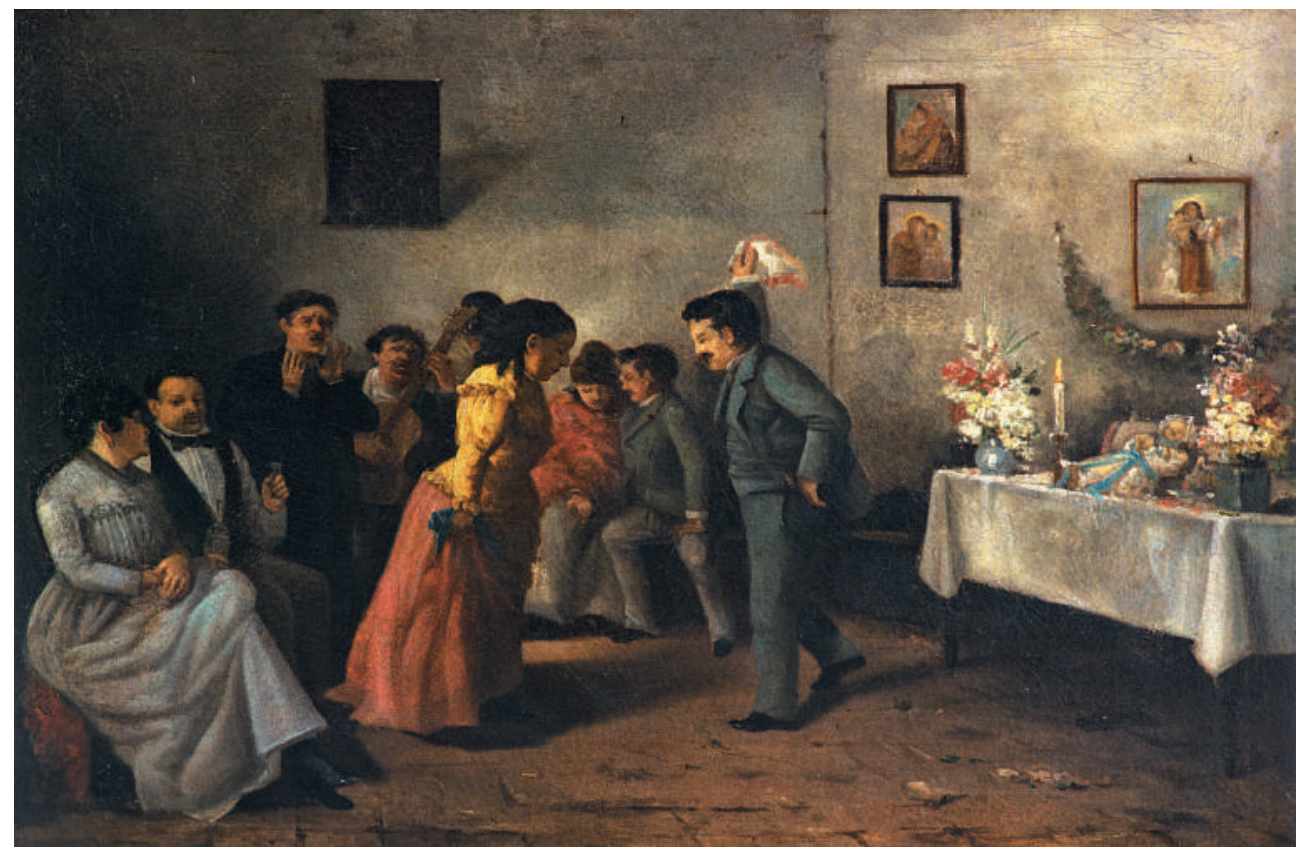

Fig.2. José Effio. El velorio del angelito (1891). Óleo sobre lienzo. Museo de Arte de Lima. Fotografía: Juan Gómez.

Proponemos una lectura autobiográfica a partir del análisis del lienzo Taller de pintura en la Biblioteca Nacional (1895). Un joven pintor, sentado y de espaldas, ejecuta un óleo en medio de una sala llena de trabajos de escultura y pintura. El ambiente al que hace referencia el título correspondería a dos estancias: la Academia Concha, ubicada en el ala derecha del primer piso, o el taller del pintor y escultor Ricardo Suarez (Pachas, 2006, p. 50). Effio, junto a Luis Ugarte y Luis Astete y Concha, tuvieron que sobrellevar la carencia de órganos integrales oficiales de enseñanza artística mediante la asistencia a talleres particulares y el autodidactismo con la copia de obras de arte. En paralelo, es explícita la intención de Effio de cohabitar con artistas peruanos reconocidos y obras paradigmáticas, como si deseara identificarse con ellos en técnica y trascendencia, aun cuando las adversidades fueron mayores. Lo anterior se demuestra con las copias de composiciones institucionalizadas del arte peruano y europeo, entre ellas, varias escenas de historia. Respecto a los artistas nacionales, reprodujo Los funerales de Atahualpa (1910) de Luis Montero, obra de formato desconocido pero publicada en la revista Mundial en 1920; La venganza del Cornaro ${ }^{18}$ (1891) de Ignacio Merino, original perdido en el incendio del antiguo Palacio de Gobierno en 1921, y La respuesta de Bolognesi (circa 1894) de Juan Lepiani. Sobre los exponentes europeos sobresalen La rixe de Ernst Meissonier, en posesión de la Sociedad de Artesanos hacia 1914 y reproducida en una portada de Mundial, y Episodio de la Guerra Franco Prusiana de 1870 (1911), copia del óleo Un episodio militar de la Ambulancia Francesa de Pedro Grovellón. ${ }^{19}$

Existe una interrelación entre la pintura de historia y el costumbrismo de Effio. A partir de su maestro atribuido, el español Ramón Muñiz, y Luis Montero, pintor referente en el siglo XIX, Effio se sitúa como el exponente transitivo de los valores de la tragedia histórica al drama individual en la pintura peruana a fin de siglo. De acuerdo con Cabrera (2004), Montero aplica en Los funerales de Atahualpa el juste milieu, la estadía intermedia entre los valores

18 Solo se conservan dos copias elaboradas por José Effio y Luis Ugarte.

19 Este cuadro también fue copiado por Luis Ugarte (Pachas, 2005, p. 104). 


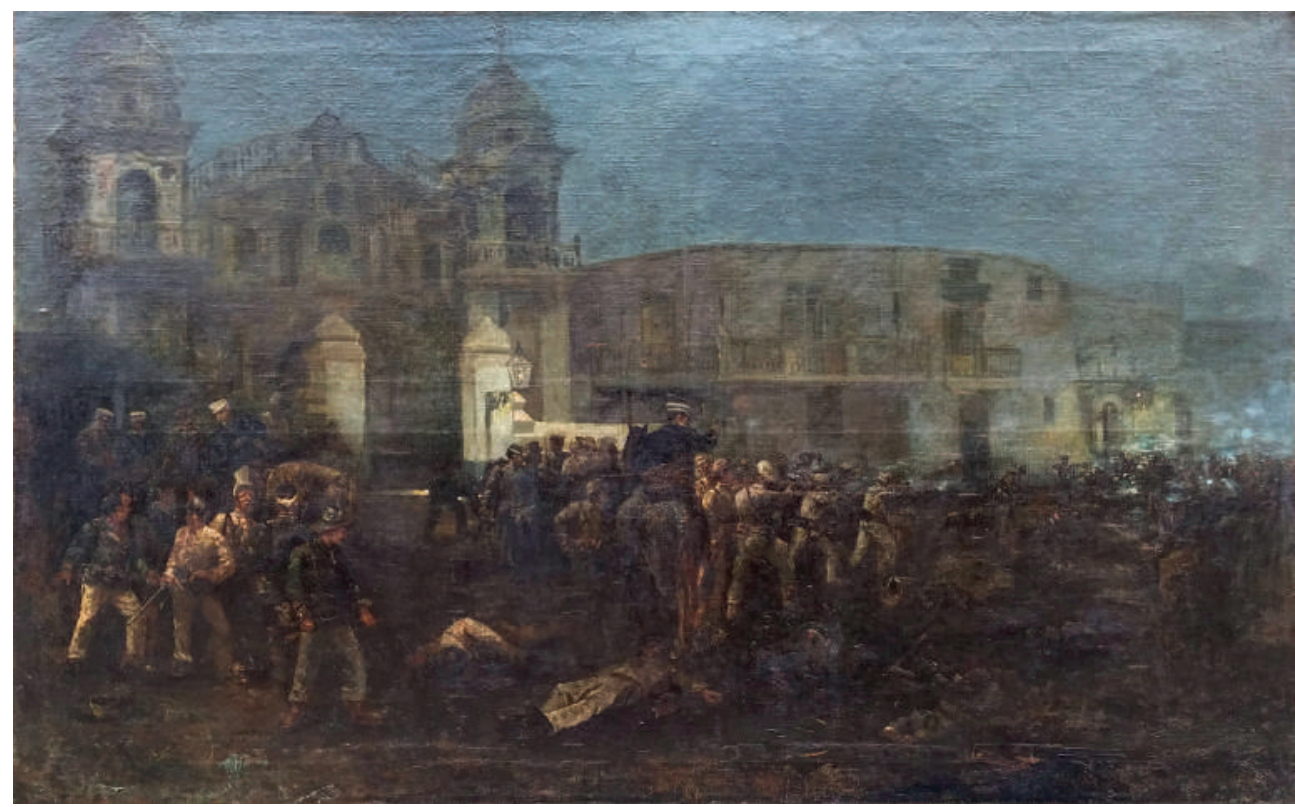

Fig.3. José Effio. La coalición de Lima (1896). Óleo sobre lienzo. Pinacoteca de la Fortaleza del Real Felipe, Callao. Fotografía: Diego Paitan. Edición Juan Gómez.

del neoclásico y el romanticismo, la pasión y la razón, así como lo verosímil y la idealización. Muñiz, mediante la muerte, enfatiza la tragedia romántica en la historia nacional con La muerte de Pizarro ${ }^{20}$ (1885) y El repase (1888). Ambos pintores no están exentos de costumbrismo: La hamaca (1855) de Montero y Zamacueca (1893) de Muñiz lo demuestran; más aún, el vínculo entre ambos con el Mercado de Piura bajo los algarrobos de Montero, que Muñiz reproduce en un Paisaje en su cuaderno de dibujos. ${ }^{21}$

Effio, además de copiar Los funerales de Atahualpa (1865-1867), se aproxima a los preceptos de su autor en La Fundación de Lima (1897-99). Sin embargo, lo luctuoso junto al dolor colectivo y la espiritualidad como mecanismo reparador deviene de una tragedia familiar anónima expuesta en su óleo costumbrista El Velorio del angelito (1891) (Fig. 2). Allí se "celebra" una muerte porque se sugestiona una posteridad favorable. El pisco, en tanto líquido, connota el agua y la vida, pero esencialmente purga el dolor de los pesantes. Finalmente, la zamacueca muta nominalmente en la Marinera en honor a la Marina de Guerra del Perú como consecuencia del conflicto con Chile, así como su práctica pasa de la jarana popular al salón de la alta burguesía.

\section{La tradición y la modernidad en la pintura de historia}

A diferencia de Fierro, Effio conoció las condiciones socioculturales dejadas tras la Guerra del Pacífico (1879-1883). De aquel conflicto germinaron estrategias discursivas para diferentes artistas locales y foráneos en el tránsito de siglos: la creación de imágenes

20 A pesar de que no fue expuesta y conocida por el público sino hasta décadas después, esta obra es uno de los primeros ejemplos pictóricos sobre el suceso histórico. De acuerdo con Paz, "congrega dramatismo y misticismo", porque se destaca, más que la muerte en sí, el tránsito doloroso hacia ella $(2019$, p. 89). Es también un espacio transitivo de momentos históricos para el devenir nacional. Se incluyen elementos anacrónicos de carga simbólica como los dos ceramios mochicas que, puestos frente a la alegoría de las artes, generan un contraste marcado de tradiciones estéticas y de poderes, devenidos por el choque cultural del siglo XVI (Ibid.).

21 Asociación sugerida, aunque no desarrollada, en Paz (2019, p. 43). 
reflexivo-reivindicativas que respondiesen la interrogante de posguerra: ¿cómo pensar y representar una nación de complejos desarrollos históricos como el Perú? Debe considerarse además el influjo de la coyuntura y trascendencia de las celebraciones del centenario independiente. En Effio, el resultado fue la creación de una imagen de la historia nacional representada por lo fúnebre, el heroísmo y la dicotomía entre tradición y modernidad.

Los procesos históricos, como la fundación de una ciudad o los estragos de conflictos bélicos, implican el cierre e inicio de etapas. La transformación radical de lo tradicional por la modernidad avasallante, es decir, la transición de formas culturales subordinadas por otras dominantes, teniendo como medio lo fúnebre, catártico y pesaroso, se denota como constante indistintamente del género elegido. En Arrieros trasportando sal22 (1912) (Fig. 1), se suscita un contraste crítico entre dos modos de transporte de carga, la tradicional con las llamas y la moderna mediante el tren, que refiere al anhelo de progreso durante la Reconstrucción Nacional. La conversión de estados ontológicos a través de la catarsis se denota en Desnudo, ${ }^{23}$ obra que representa a una joven semidesnuda, pesarosa, de cabellera ensortijada y profusa, corona de flores, paño negro que cubre la parte inferior del cuerpo y sentada en un campo de pétalos esparcidos. Las características formales la emparentan con El Cántaro roto o La virginidad perdida de Juan Lepiani, y en ambas escenas el asunto explícito es la pérdida de la virginidad.

El propósito, aunque tácito, es condensar la continuidad histórica (individual / colectiva / identitaria) en una escena trágica seleccionada, en donde la interpretación del artista determina desenlaces disyuntivos: afianzarse al novel proyecto o anhelar su reversión. La opinión pública, especializada o no, con participación activa si refiere a su actualidad, puede legitimarlos al reconocer en ellos enclaves de respaldo identitario o, en otros casos, formas de reconstitución.

Tal fue el caso de La Fundación de Lima (1897-99) (Fig. 4), óleo participante del Concurso Concha, exposición promocional para artistas nacionales que congrega los conceptos señalados en conflicto. La escena representa el acto fundacional de la ciudad mediante la bendición de la primera piedra ante la presencia de Francisco Pizarro, el 18 de enero de 1535, en un descampado valle del río Rímac. Están presentes, además de la comitiva militar española con alabardas y estandarte real, el poder religioso a través de dos mercedarios, tres dominicos, un Cristo crucificado y las sagradas escrituras sobre atril, así como el grupo étnico sometido, representado por una niña y seis mujeres indígenas. A la profusa decoración de los enseres y vestimentas, se suma el erotismo de los senos escotados, aspecto discordante con la melancolía de los rostros femeninos.

A pesar de no obtener el primer puesto debido a errores compositivos, fue premiada con una medalla de plata ${ }^{24}$ y 100 soles. La opinión contemporánea sobre la obra permitió que el autor sugiriera su donación al Concejo Provincial de Lima, así como el idóneo lugar de

22 El título y la reproducción de la obra aparecen en el catálogo de la XIX subasta anual del MALI, realizado el 25 de octubre del 2014. Precisamos un error en la denominación. En las bolsas que trasportan los arrieros se aprecia el nombre "Juan V. Peral". Juan Vicente Peral (1846-1910) fue un agente industrial español residente en el Perú desde 1868, dedicado al comercio de la harina de trigo y del servicio eléctrico mediante la empresa Trust Eléctrico. En 1905, Alejandro Garland resalta la industria molinera de Juan V. Peral entre las nueve existentes en Lima, a pesar de que un incendio en 1904 destruyera sus instalaciones. Peral repotenció su maquinaria al adquirir prototipos modernos a base del sistema de cilindros. Producía hasta 40000 kilogramos de harina por día mediante fuerza hidráulica y vapor (Garland, 1905, p. 129). Por lo dicho, las bolsas contendrían harina de trigo y no sal; además, la composición demostraría el desarrollo progresivo del comercio a gran escala de un particular.

23 Renombramos el título del cuadro de forma provisoria según sus características formales. Este óleo sobre madera fue reproducido en la biografía sobre José Effio escrita por Luis Ugarte y fue denominado como Sin título (Pachas, 2005, p. 43). Se desconoce la ubicación actual de la obra, así como las dimensiones reales.

24 Concurso, 1897, pp. 2-3. 
exposición: el salón de sesiones, lo cual se concretó posteriormente. ${ }^{25}$ El cuadro de Effio se constituyó como elemento de resguardo identitario-político en un espacio oficial comparándose con el Retrato de José Olaya (1828) de Gil de Castro para la Municipalidad de Chorrillos y Los Funerales de Atahualpa de Luis Montero, delegado al Congreso de la República. La Fundación de Lima es el primer registro de un asunto histórico fundacional en las artes visuales durante la República, además de ser el único ejemplar existente sobre la primera misa en el Perú realizada en el siglo XIX. ${ }^{26}$ La deferencia inicial sobre el óleo no detuvo la desidia posterior: ${ }^{27}$ en 1993 La Fundación fue encontrada enrollada y en pésimas condiciones en el Museo de la Cultura Peruana (Carrasco, 1993, p. 91).

\section{El héroe y lo fúnebre}

De acuerdo con Hugo Bauzá, entre los aspectos morfológicos de los héroes se considera que condensan dos naturalezas: adquieren una esencia divina por concentrar valores utópicos, pero se retrotraen a la mortalidad por su humanismo. Son fungidos por "un móvil ético" y preservan el principio de solidaridad y acción social, en alusión a la categoría de "fundadores de ciudades" del historiador Thomas Carlyle (Bauzá, 2007, p. 5). A través del tiempo, son tomados como arquetipos y, por ende, modelos de las divisas colectivas. Sus ansias por la transformación les confiere una naturaleza trasgresora, pero no miden los límites trágicos de sus acciones y terminan gozando del "espejismo de la inmortalidad"; una fama perecedera. Finalmente, su impronta legitima una racionalidad dominante entre los aspectos irracionales internos, y se constituye como el principal mediador en el conflicto entre dos mundos (Bauzá, 2007, p. 8).

El conflicto cultural del siglo XVI se reaviva en el siglo XIX debido a la Guerra del Pacífico. Iniciada el 5 de abril de 1879, se enfrentaron Bolivia y Perú contra Chile en razón al aumento de impuestos en la explotación de salitre a las empresas chilenas. La defensa de la autonomía nacional frente a la transgresión foránea está emparentada con las pinturas sobre este evento bélico y fueron el tema de las composiciones que realizó Effio para la exposición del Centro Artístico de 1887. El jurado destiló comentarios favorables a sus obras, en especial dos óleos cuya interpretación histórica del conflicto ${ }^{28}$ (Gutiérrez, 1887) reflejaban su creatividad y originalidad. Fue previsible su recepción favorable por situarse en el marco de las celebraciones de Fiestas Patrias, además de suceder a pocos años del cese de la guerra. Sin embargo, aquel esplendor de una gloria ficticia, bajo el espectro de lo fúnebre por la caída del héroe enemigo y el recuerdo del territorio, el héroe y bienes nacionales perdidos, recae en otra obra de la exposición, denominada El muelle de Iquique con el cadáver de Arturo Prat ${ }^{29}$ (1887) (Fig. 5), hallada en una colección particular de Santiago de Chile.

25 Pachas (2006, p. 72). Effio demoró dos años más para finalizar el lienzo, acción previsible para corregir o ampliar algún detalle que fue observado durante el concurso.

26 En 1900, Juan Lepiani esbozó un cuadro sobre la fundación limeña para el mismo espacio, respaldado económica e institucionalmente, pero que no se derivó al óleo. En el estudio acucioso sobre Lepiani, la historiadora de arte Ana Karina Saldaña plantea que la causa se debió a irregularidades en la subvención municipal acordada tras el cambio de gestión, según el Acta de Sesión del Honorable Concejo Provincial de Lima de marzo de 1901 (Saldaña, 2018, p. 68). La problemática de fondo reside en conocer qué motivó el encargo de una composición nueva de un tema ya instituido por otro cuadro logrado.

27 No se conoce bajo qué circunstancias La Fundación de Lima fue enviada al Museo Nacional, en la actualidad en las instalaciones del MNAAH.

28 Los dos óleos citados son Batalla de Huamachuco y Batalla de Tarapacá. Se encuentran en la Casa de la Moneda de Potosí. No se determina los móviles del traslado. Effio realizó cuatro obras sobre la Guerra con Chile, las primeras de su producción. Además de las dos descritas, están Vista de Iquique y El muelle de Iquique con el cadáver de Arturo Prat.

29 El capitán Arturo Prat Chacón es el principal héroe naval chileno. El 5 de abril de 1879 dirigió el blindado Blanco Encalada hacia la bahía peruana de Iquique para notificar el inicio del conflicto. Durante la guerra, Prat dirigió la corbeta Esmeralda. El 21 de mayo se instalaron baterías en el muelle para bombardearla desde tierra, las cuales fueron efectivas. Finalmente, los espolonazos del Huáscar la derribaron (Wilson, 2014, p. 155). 


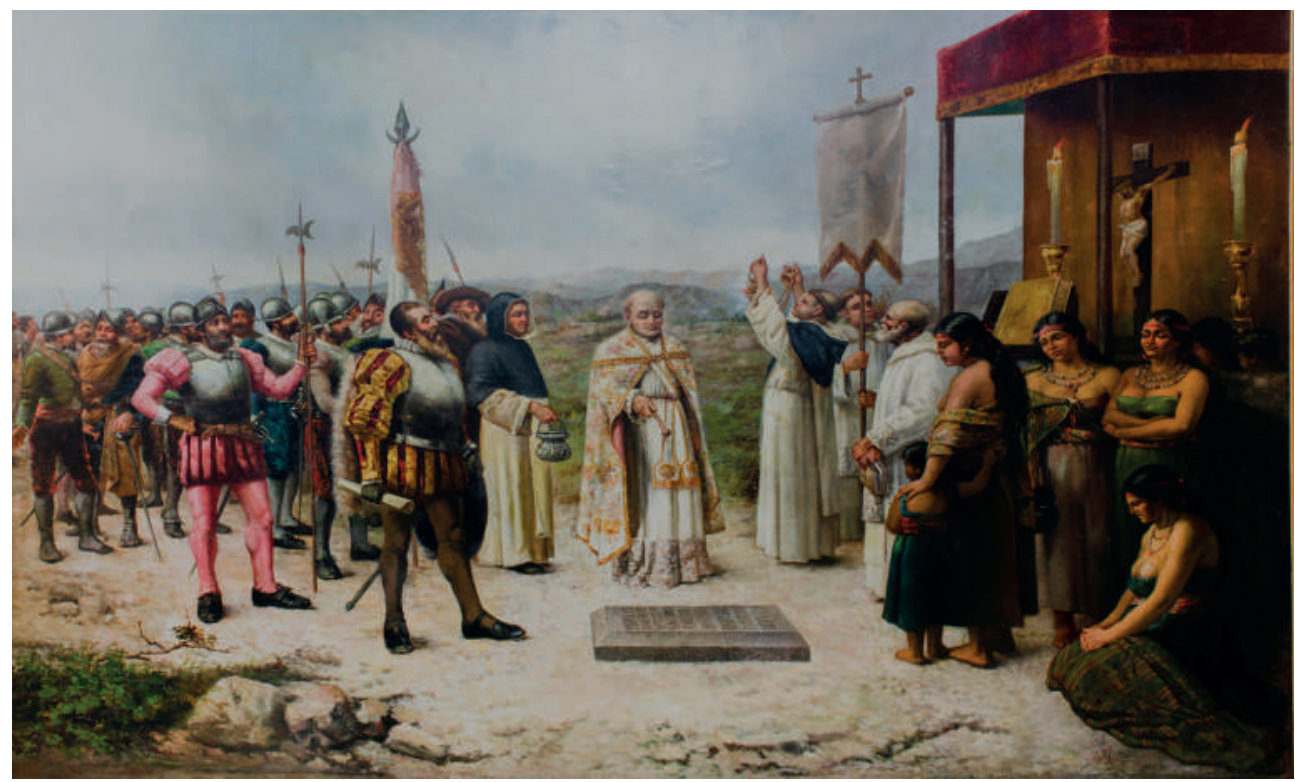

Fig.4. José Effio. La fundación de Lima (1897-1899). Óleo sobre lienzo. Museo Nacional de Arqueología, Antropología e Historia del Perú. Fotografía Diego Paitan.

La escena posee diferentes aristas. La exposición del cadáver del héroe chileno, puesto hacia el espectador y a la mirada de distintos civiles y militares peruanos, se configura como una victoria artificial. Iquique funge como recuerdo hiriente de la expropiación rival. El monitor peruano Huáscar, referente material bañado en aura de heroísmo por sus tripulantes, denota su marcha a lo lejos, triunfante, tras dejar en tierra al héroe chileno y los sobrevivientes la tarde del 21 de mayo en Iquique, pero rumbo a inmolarse. Coincidentemente, y en defensa del decoro nacional, al año siguiente de finalizado el óleo, la Marina chilena repatría los restos de Prat hacía Valparaíso mediante el botín de guerra, el Huáscar. ${ }^{30}$ La carga simbólica del monitor implica también a la acción heroica de su comandante, Miguel Grau Seminario, quien asistió a los heridos chilenos durante el enfrentamiento naval, y junto a los muertos enemigos, los derivó a la bahía de Iquique, entre ellos a su homólogo Prat. En la carta de Grau a Carmela Carvajal, viuda de Prat (reproducido en Ahumada, 1888, p. 305), se denota la sensible amplitud humana del comandante del Huáscar ante la noción de la defensa de la patria, peruano y chilena, que implica la ofrenda de la vida, del honor y la memoria individual. Se reconoce una actitud heroica loable en Prat antes de ver al enemigo y una racionalidad moral surgida entre la pasión bélica. La memoria preservada en el Huáscar, Iquique o los bienes entregados a la viuda de Prat, evocan y depuran, de forma cíclica, la ausencia física de ambos héroes.

Finalmente, un actor importante en el conflicto señalado también se adecuó a la coyuntura política limeña de fin de siglo. En 1896, las vidrieras de la Casa Galland expusieron dos cuadros de Effio: La Coalición de Lima, o conocida en la actualidad como La entrada de Piérola por Cocharcas, y Un puesto de Guardia. ${ }^{31}$ El asunto del primer cuadro fue recreado también por Juan Lepiani y Martín Ruilova. En la actualidad, la escena más difundida, así como recordada en el imaginario colectivo, es la de Lepiani. En su momento, el cronista Lorenzo de Medicis catalogó a la obra de Effio como superior a la de Lepiani, aunque opacada y menos detallada que

30 Ibid.

31 Esta última también es conocida como El Retén del Puente Balta. Representa las vicisitudes de las clases sociales peruanas frente al sitio de Lima por las tropas chilenas. En 1914, el lienzo fue propiedad de Pedro Berrio, impresor activo a inicios del siglo XX. 


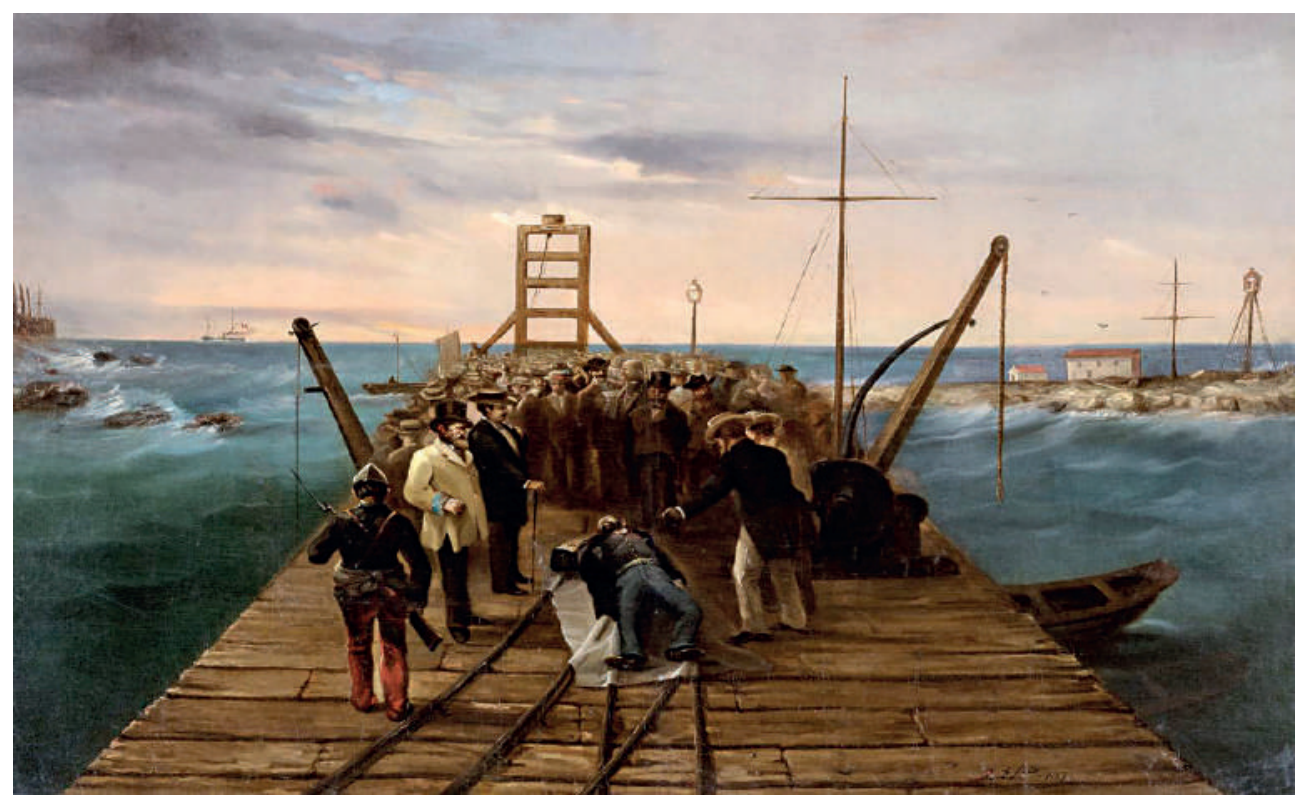

Fig. 5. José Effio. El muelle de Iquique con el cadáver de Arturo Prat (1887). Óleo sobre lienzo. Colección particular, Santiago de Chile. Fotografía Pablo Maldonado Castro.

la de Ruilova (1896); mientras que para el crítico Marcial fue la mejor interpretación histórica del conflicto civil. ${ }^{32}$ Pese a ello, ambos cronistas admiran el despliegue del velo humoso que opaca los cuerpos, estáticos por el "sedentarismo", debido a la media hora que se quedaron las tropas de Piérola frente a la Iglesia de Cocharcas, y la polvareda de los fusiles, como un “eclipse de luz". Este Piérola, a caballo blanco, cual héroe mesiánico que congregaba los valores populares frente al segundo Gobierno de Cáceres, se disocia del furtivo presidente que entorpeció las acciones políticas durante la Guerra con Chile, y quedó a merced de una enfurecida crítica por los revisionistas de la historia peruana en el siglo XX.

Así, Effio presenta la figura del héroe, pero como individuo catártico, que tras una introspección decide superar los errores pasados y asumir las riendas de un "estado empírico, desorganizado e improvisado" (Quiroz, 2013, p. 212) dejado por el partido constitucionalista, aunque, como acto reflejo, se trataba de una depuración de sus acciones pasadas. Aquella transición hacia la modernidad deseada por la reconstrucción nacional, posguerra y poscacerismo no era imaginado para Clorinda Matto de Turner y Manuel González Prada, quienes vieron en aquel héroe a su propia antítesis, "un bárbaro prehistórico en medio de una civilización moderna, representante de todo lo que se hallaba torcido y deficiente en la historia peruana" (Quiroz, 2013, p. 209).

La pintura de historia de Effio es un diálogo sobre el tránsito de tiempos y formas culturales, todos con un desenlace condensado que remite a lo fúnebre, donde los héroes y grupos humanos moderan el devenir colectivo, si bien con anhelo a lo próspero, doloroso. La actitud revanchista posguerra y la esencia romántica del mártir popular están inmersos en la melancolía por el pasado perdido, la herencia segmentada de lo tradicional, para dar paso a la modernidad y sus promesas. Effio utilizó el discurso fúnebre como agente regulador del héroe que promueva la superación de condiciones desfavorables a gran escala: de reflexionar lo perdido en hechos cruciales colectivos a esbozar un mejor devenir para la sociedad peruana.

32 Su crítica no fue homogénea ni indulgente con Effio. Para Marcial, el pintor carecía de estudios serios de pintura, sin visitas a pinacotecas célebres ni parentesco con profesores inmortales (Marcial, 1896, p. 270). 


\section{Referencias bibliográficas}

Ahumada, P. (1888). Guerra del Pacífico. Recopilación completa de todos los documentos oficiales, correspondencias y demás publicaciones referentes a la guerra de que ha dado a luz la prensa de Chile, Perú y Bolivia. Tomo I. Valparaíso: Imprenta del Progreso.

Anónimo (1937). De Arte. "La confesión", óleo de valor artístico e histórico. La Prensa, 24 de marzo, p. 8.

Bauzá, H. (2007). El mito del héroe. Morfología y semántica de la figura heroica. Buenos Aires: Fondo de Cultura Económica.

Cabrera, M. (2013). Academicismo y retrato en la obra pictórica de Luis Montero. (Tesis de Licenciatura). Universidad Nacional Mayor de San Marcos, Lima.

Carrasco, S. (1993). Alto ahí. Caretas (1266), pp. 90-91.

Concurso Concha (1897). El Comercio, 27 de diciembre, pp. 2-3.

Garland, A. (1905). Reseña Industrial del Perú. Lima: Ministerio de Fomento.

Gutiérrez, E. (1887). Centro Artístico. El Comercio, 2 de agosto, pp. 4-5.

Herrera, J. (1935). Repartimiento en tierras y solares en la ciudad de los reyes y sus anexos. Boletín de la Sociedad Geográfica de Lima (52), pp. 19-20.

Kermode, F. (1985). Forms of attention. Chicago: The University of Chicago Press.

León, G. (2004). Apuntes histórico genealógicos de Francisco Fierro: Pancho Fierro. Lima: Biblioteca Nacional del Perú.

Leonardini, N. (1998). Los italianos y su influencia en la cultura artística peruana en el siglo XIX. (Tesis de doctorado). Universidad Nacional Autónoma de México, México D. F.

Lorenzo de Médicis (1896). Entrada de la Coalición a Lima. La Neblina (12), pp. 270-271.

Macera, P. (2000). Parlamento y sociedad en el Perú. Tomo V. Lima: Fondo Editorial del Congreso de la República.

Majluf, N. (1997). Nueva adquisición. José Effio, El velorio del angelito. En Boletín del Museo de Arte de Lima (209), Lima: MALI, 1-2.

Marcial (1896). Crónicas Marciales. La Neblina (3), pp. 48-49.
Mujica, M. (2013). Perú, 10.000 años de pintura. Lima: Fondo Editorial USMP.

Núñez, T. (1975). José Effio (1840-1900?). En Pintura Contemporánea, Lima: BCP, pp. 142-145.

Pachas, S. (2005). Nuestros artistas. Lima: Seminario de Historia Rural Andina.

Pachas, S. (2006). Los concursos de arte Concha (1890-1917). Lima: Seminario de Historia Rural Andina.

Paz, G. (2019). Ramón Muñiz y Cano y su producción pictórica en Lima: La muerte de Pizarro y El repase. [Tesis de licenciatura]. Universidad Nacional Mayor de San Marcos, Lima.

Quiroz, A. (2013). Historia de la corrupción en el Perú. Lima: Instituto de Estudios Peruanos.

Saldaña, A. (2018). La historia nacional en la pintura de Juan Lepiani. [Tesis de licenciatura]. Universidad Nacional Mayor de San Marcos, Lima.

Tello, G. (1997). Pinturas y pintores del Perú. Lima: C \& C Servicios Especializados.

Tovar, S. (1994). Testimonios del siglo XIX. Oiga (722), pp. 53-54.

Ugarte, J. (1984). Panorama de la Pintura en el Perú Republicano. En Raíces peruanas en el Arte Contemporáneo. Arequipa: BCP, pp. 5-31.

Ugarte, J. (2001). Monumenta Limensis. Lima: Fondo Editorial de Congreso del Perú.

Ugarte, L. (1914). José Effio. Artista nacional. La Prensa, 17 de diciembre, p. 7.

Wilson, F. (2014). El monitor Huáscar: un buque histórico. En Prat (1848-1879) pp. 150-155. Santiago de Chile: Banco Santander, Telefónica Chile, Corporación Arturo Prat.

Recibido el 26 de marzo de 2020 Aceptado el 16 de septiembre de 2020 